\title{
Essential Thrombocythemia Diagnosed from a Toe Ulcer
}

\author{
Rieko Sekine ${ }^{1}$, Hisao Hara ${ }^{2}$, Reiko Tsukuura ${ }^{3}$ and Naohiko Aozasa ${ }^{4}$
}

Key words: essential thrombocythemia, toe necrosis, ulcer

(Intern Med 60: 2873-2874, 2021)

(DOI: 10.2169/internalmedicine.6900-20)
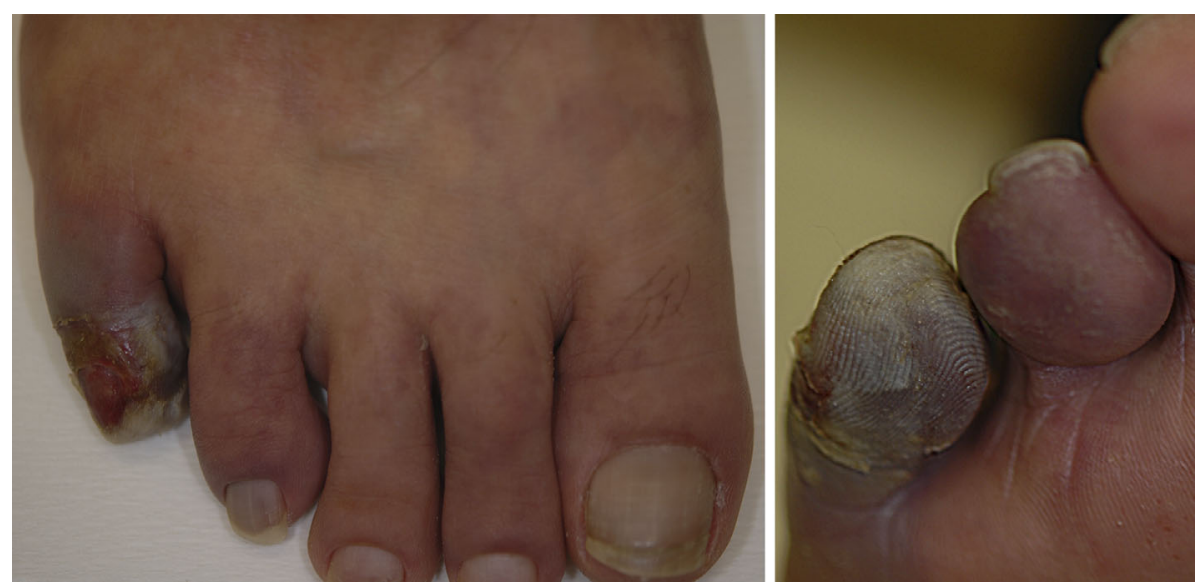

Picture 1.
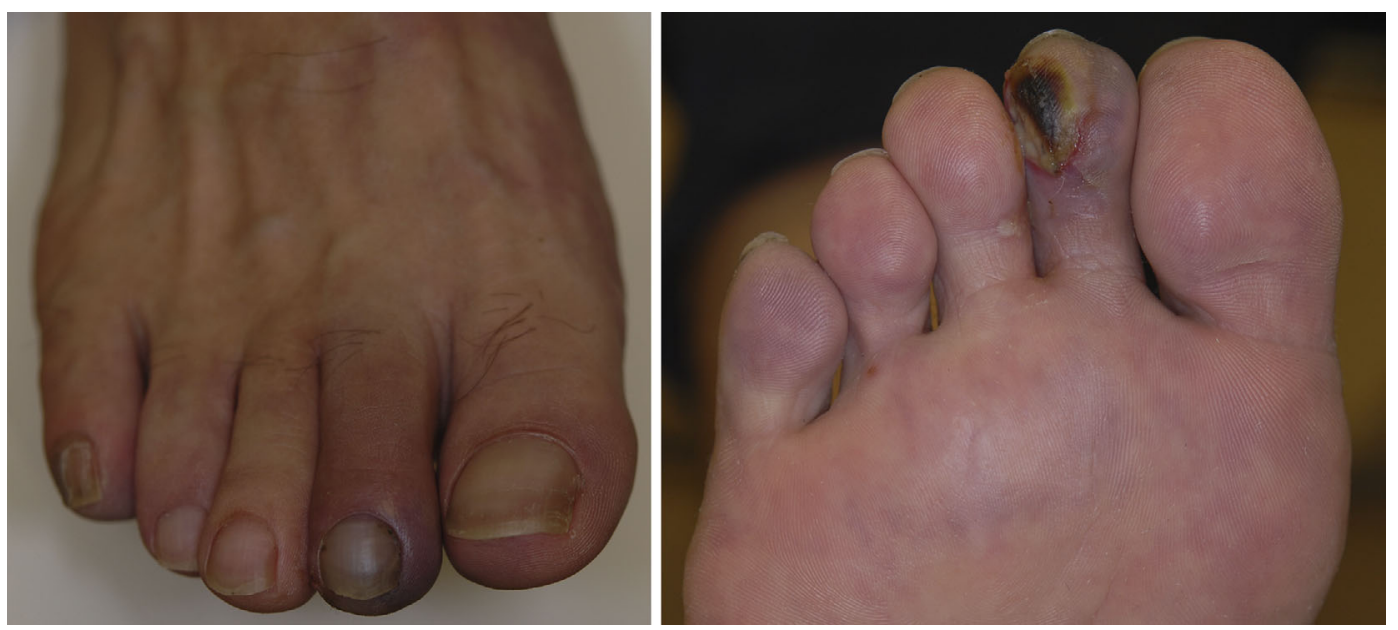

Picture 2.

A 62-year-old, diabetic, male patient presented with a painful, right fifth toe ulcer resulting from a shoe bite (Picture 1). The patient's diabetes had been relatively well- controlled for over ten years with HbA1c ranging from 6$7 \%$. Two years earlier he noticed another ulcer on his right second toe (Picture 2). A catheter examination at the time

\footnotetext{
${ }^{1}$ Division of Hematology, National Center for Global Health and Medicine, Japan, ${ }^{2}$ Division of Cardiovascular Medicine, National Center for Global Health and Medicine, Japan, ${ }^{3}$ Department of Plastic and Reconstructive Surgery, National Center for Global Health and Medicine, Japan and ${ }^{4}$ Department of Dermatology, National Center for Global Health and Medicine, Japan

Received: December 8, 2020; Accepted: February 4, 2021; Advance Publication by J-STAGE: March 22, 2021

Correspondence to Dr. Naohiko Aozasa, naozasa@hosp.ncgm.go.jp
} 
showed no vascular occlusion or stenosis. The wound healed in four months with oral beraprost treatment. Beraprost was stopped one month before the current visit because no further ulceration developed. A blood analysis showed WBC $18,840 / \mu \mathrm{L}$ and platelets $101.5 \times 10^{4} / \mu \mathrm{L}$. A JAK2-V617F mutation and bone marrow findings led to the diagnosis of essential thrombocythemia (ET). The affected toe was amputated due to the onset of gangrene. Bayaspirin and hydroxycarbamide were started, and the complete blood count improved (1). A toe ulcer or gangrene usually indicates a circulatory disorder such as arteriosclerosis obliterans, but ET should also be considered in the differential diagnosis as a possible underlying disease (2).
The authors state that they have no Conflict of Interest (COI).

\section{References}

1. Tefferi A, Pardanani A. Essential thrombocythemia. N Engl J Med 381: 2135-2144, 2019.

2. Itin PH, Winkelmann RK. Cutaneous manifestations in patients with essential thrombocythemia. J Am Acad Dermatol 24: 59-63, 1991.

The Internal Medicine is an Open Access journal distributed under the Creative Commons Attribution-NonCommercial-NoDerivatives 4.0 International License. To view the details of this license, please visit (https://creativecommons.org/licenses/ by-nc-nd/4.0/).

(C) 2021 The Japanese Society of Internal Medicine Intern Med 60: 2873-2874, 2021 